\title{
Pulmonary Kaposi's sarcoma in two recipients of renal transplants
}

\author{
K A GUNAWARDENA, M K AL-HASANi, A HALEEM, M Al-SUlEimaN, \\ A A AL-KHADER
}

From the Departments of Respiratory Medicine, Nephrology, and Histopathology, Riyadh Military Hospital, Riyadh, Saudi Arabia

\begin{abstract}
Among 350 recipients of renal transplants seen at the Riyadh Military Hospital, 12 developed Kaposi's sarcoma. Two of these sarcomas presented primarily as a problem of diffuse lung infiltrates in an immunocompromised host. In one the diagnosis was established by transbronchial lung biopsy. Withdrawal of immunosuppression led to satisfactory radiological resolution in both patients.
\end{abstract}

Kaposi's sarcoma is a malignant neoplasm that has recently come to the fore because of its frequent occurrence in the acquired immune deficiency syndrome (AIDS). ${ }^{12}$ Kaposi's sarcoma affecting the lungs is well documented in AIDS, ${ }^{3-6}$ and often follows sarcomas of the skin, gastrointestinal tract, and lymph nodes. Kaposi's sarcoma is less common in recipients of renal transplants and presentation with lung infiltration has not been documented before. We report two such cases, in one of which the diagnosis was made by transbronchial biopsy, a procedure that has been reported to be unsatisfactory ${ }^{34}$ and possibly dangerous ${ }^{6}$ in pulmonary Kaposi's sarcoma.

\section{Case reports}

\section{CASE 1}

A 24 year old Saudi man had a cadaveric renal transplant in July 1985 . He was immunosuppressed with prednisolone and cyclosporin. An episode of acute cellular rejection in October 1985 was treated with intravenous methyl prednisolone for three days followed by azathioprine. In January 1986 he developed a low grade fever, a small right pleural effusion, and fine reticulonodular shadowing in both lungs. There were no respiratory symptoms. The effusion cleared spontaneously, but four months later he was readmitted because a routine chest radiograph showed recurrence of the effusion and extensive reticulonodular shadowing (fig la). He complained of abdominal pain, intermittent melaena, and pain in the low back and right lumbar region. Although tachypnoeic with a respiratory rate of $30 / \mathrm{min}$ he had no respiratory symptoms. His temperature was $36.5^{\circ} \mathrm{C}$. Apart from the signs of an effusion a few inspiratory crackles were present bilaterally. His haemoglobin concentration and white blood

Address for reprint requests: Dr K A Gunawardena, Riyadh Military Hospital, PO Box 7897, Riyadh 11159, Saudi Arabia.

Accepted 11 January 1988
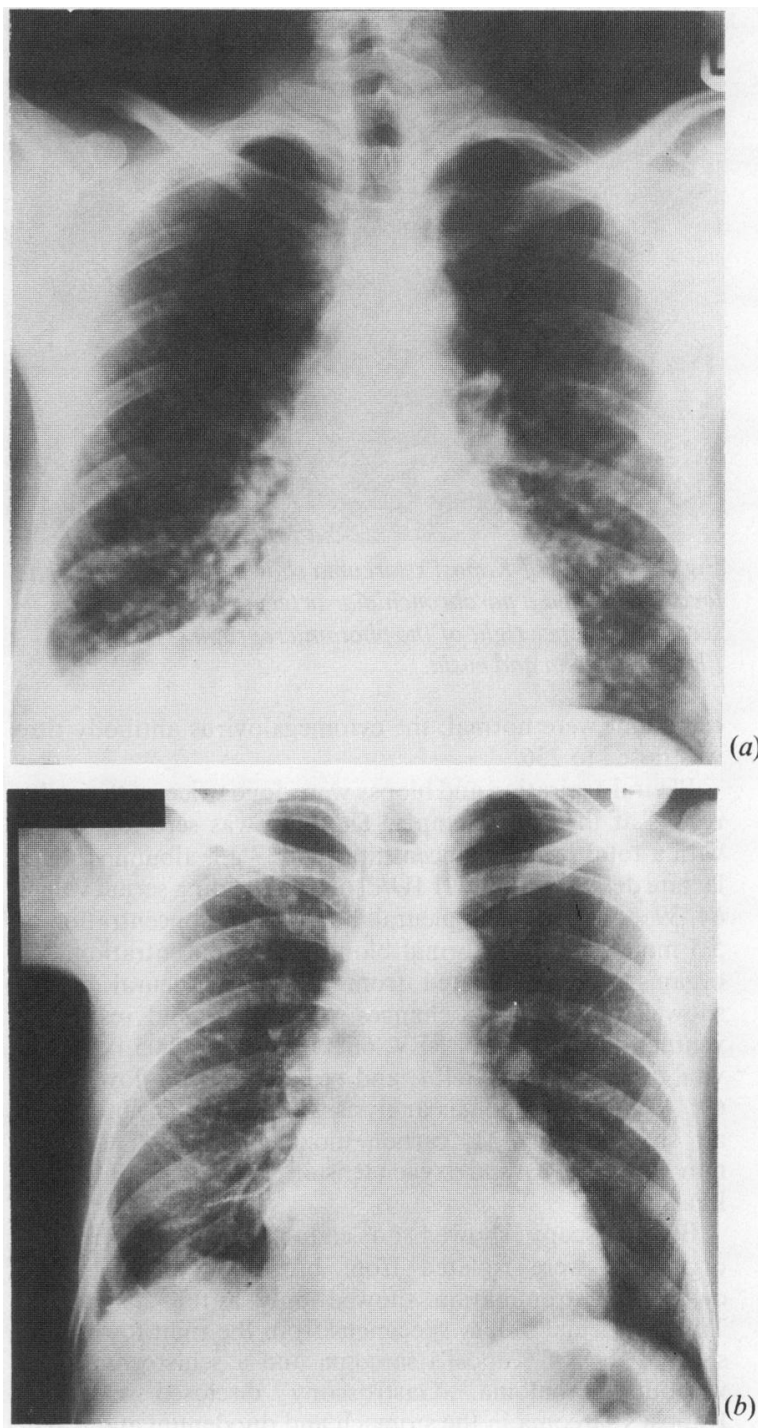

Fig 1 Case 1: (a) Chest radiograph showing right pleural effusion and bilateral reticulonodular infiltrates. (b) Partial clearance of the infiltrates after withdrawal of immunosuppression. 


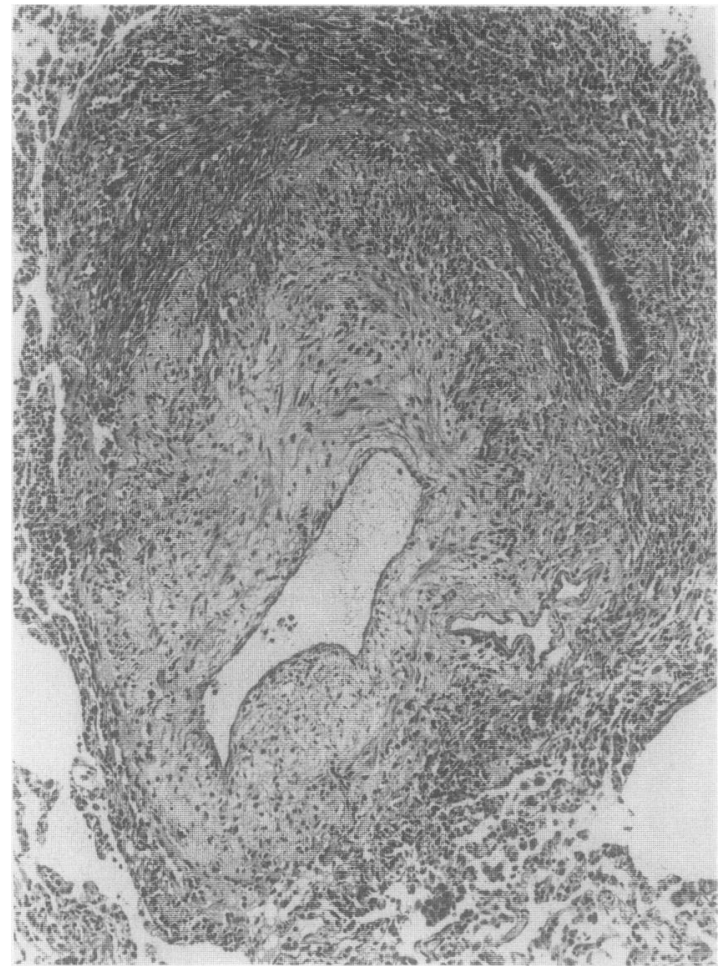

Fig 2 Nodule of Kaposi's sarcoma showing its characteristic location around a parabronchiolar artery; the bronchiole is seen in the upper right of the photomicrograph. (Haematoxylin and eosin.)

cell count were normal; the cytomegalovirus antibody titre was raised to 256 .

Pleural aspiration and biopsy were done twice, with similar results at the two attempts. The fluid was serosanguinous with a total protein concentration of $37 \mathrm{~g} / \mathrm{l}$, albumin $24 \mathrm{~g} / \mathrm{l}$, lactate dehydrogenase $91 \mathrm{IU} / \mathrm{dl}$ (corresponding serum values 64,39 , and 215) and a pleural fluid glucose concentration of $5.5 \mathrm{mmol} / \mathrm{l}$, with a normal blood sugar concentration. No organisms were isolated from the fluid. Pleural biopsy showed only reactive changes. He had a mild restrictive ventilatory defect with FEV $66 \%$ predicted $(2.051)$, forced vital capacity (FVC) 64\%, and peak expiratpry flow (PEF) $69 \%$. Arterial blood gas analysis with the patient breathing air showed $\mathrm{pH} \mathrm{7.41}$, carbon dioxide tension $\left(\mathrm{PaCO}_{2}\right) 29$ $\mathrm{mm} \mathrm{Hg}(3.9 \mathrm{kPa})$, and oxygen tension $\left(\mathrm{PaO}_{2}\right) 80 \mathrm{~mm} \mathrm{Hg}(10.7$ $\mathrm{kPa})$.

Bronchoscopy showed no endobronchial lesions. No organisms were isolated from bronchial washings and cytological examination showed only a few histiocytes. Transbronchial biopsy specimens from the right lower lobe showed foci of Kaposi's sarcoma and a schistosomal egg without granuloma. Gastroscopy disclosed extensive Kaposi's sarcoma in the stomach and duodenum and a skin biopsy specimen from a minute suspicious lesion also showed Kaposi's sarcoma. Computed tomography of the abdomen showed enlarged para-aortic nodes and infiltration of the right psoas muscle.
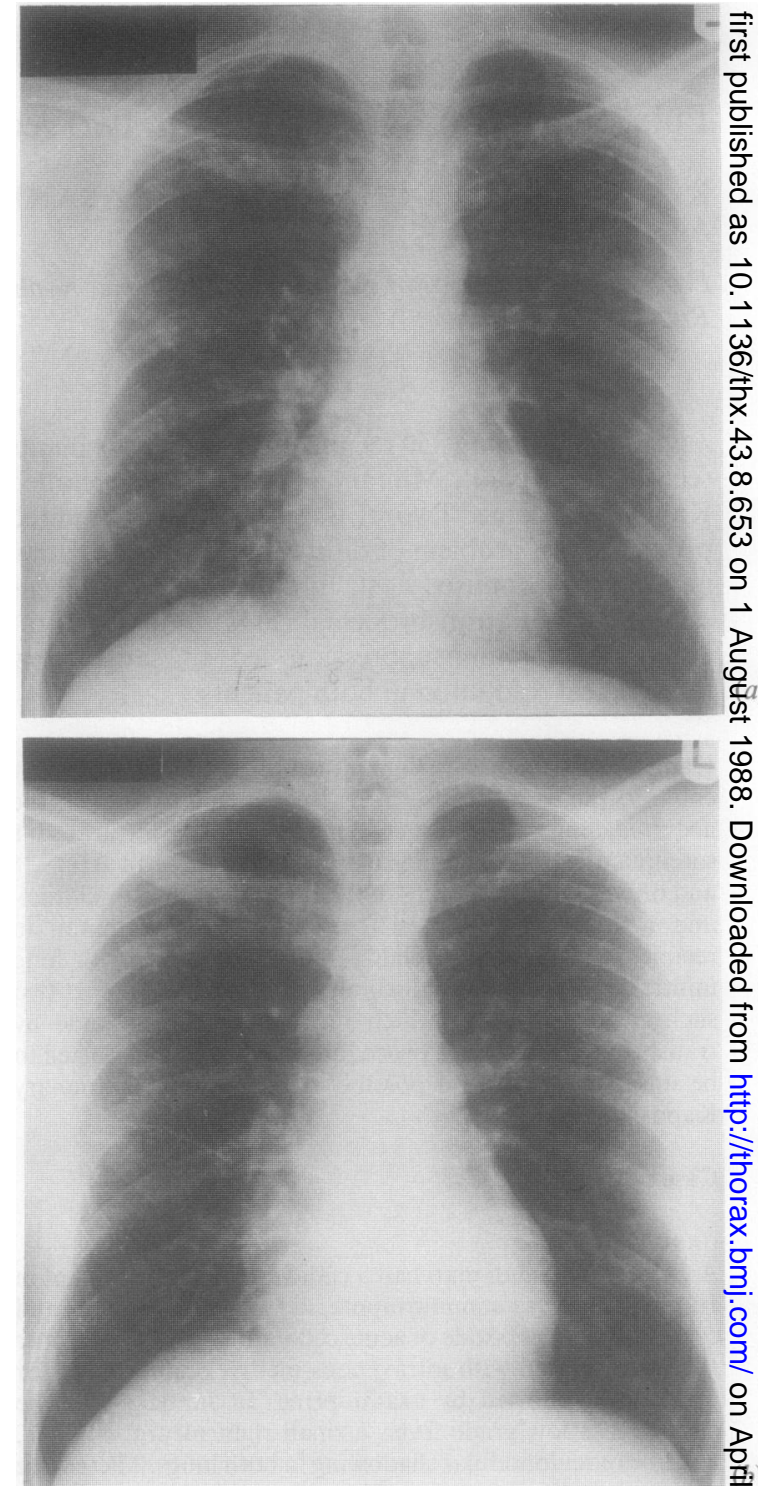

Fig 3 Case 2: (a) Chest radiograph showing diffuse bilateral reticulonodular infiltrates. (b) Improvement after withdrawal of immunosuppression.

In view of these findings immunosuppressive treatment 2 was stopped. He developed a fever and became increasingly $\varrho$ short of breath, which was not relieved by the removal of $\mathbb{D}$ 1.21 of fluid from the chest. His arterial blood gas tensions :deteriorated $\left(\mathrm{PaO}_{2} 66 \mathrm{~mm} \mathrm{Hg}(8.8 \mathrm{kPa})\right.$ while he was breathing air).

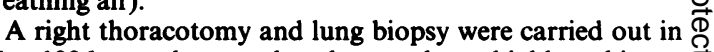
May 1986 to make sure that the transbronchial lung biopsy $\overrightarrow{\mathbb{D}}$ had not missed an opportunistic infection. The right chest 응 contained serosanguinous fluid. The lung was adherent to the parietal pleura. Multiple dark red nodules were seen on the $\delta$ 
surface. Biopsy specimens from the right lower and middle lobes showed multiple nodules of Kaposi's sarcoma around vessels and bronchioles (fig 2). Adjacent alveoli showed fibrinous exudate and haemosiderin containing histiocytes. The lung parenchyma showed scattered schistosoma eggs and diffusely scattered chronic inflammatory cells. There was no evidence of pneumocystis or cytomegalovirus infection.

The patient made a gradual and slow recovery, but his renal function deteriorated. By July 1986 the chest radiograph showed considerable improvement (fig $1 b$ ), gastroscopic appearances were normal, and computed tomography of the thorax and the abdomen showed no evidence of disease. He remains well with thrice weekly haemodialysis.

\section{CASE 2}

A 27 year old Sudani man had a full match live donor transplant from his brother in November 1985. Immunosuppression was initially with cyclosporin and prednisolone; when renal function was stable azathioprine was substituted for cyclosporin.

In April 1986 he developed general malaise, dull aching chest pains, and a dry cough. There was no fever, dyspnoea, or haemoptysis. Chest radiography showed bilateral reticulonodular infiltrates of very much the same pattern as in case 1 (fig $3 a$ ). Two weeks later he developed epigastric and hypochondrial pains, occasional vomiting, and melaena. When seen by us for the first time in May he looked generally well but pale and lung auscultation indicated nothing abnormal. There was moderate epigastric tenderness.

Investigations showed a haemoglobin concentration of 8.7 $\mathrm{g} / \mathrm{dl}$, a white blood cell count of $4.5 \times 10^{9} / \mathrm{l}$, and a cytomegalovirus antibody titre below 8 . Computed tomography of the abdomen showed a mass in the right lobe of the liver and enlarged para-aortic nodes. Lung function tests showed a moderately severe restrictive defect with $\mathrm{FEV}, 50 \%$ predicted (1.7 l), forced vital capacity (FVC) $40 \%$, peak expiratory flow (PEF) $48 \%$, single breath transfer factor (TLCO) $36 \%$, and transfer coefficient (KCO) $125 \%$ predicted. $\mathrm{PaO}_{2}$ with the patient breathing air was $71 \mathrm{~mm} \mathrm{Hg}(9.5 \mathrm{kPa})$, and $\mathrm{PaCO}_{2} 38 \mathrm{~mm} \mathrm{Hg}(5 \cdot 1 \mathrm{kPa})$. Bronchoscopy and transbronchial lung biopsy were uninformative.

An open lung biopsy was carried out from the right middle lobe in May. This showed multiple nodules of Kaposi's sarcoma, mainly of perivascular distribution. No granulomas, cytomegalovirus, or pneumocystis were seen. Endoscopy showed multiple bluish red nodules in the stomach and colon. Biopsy specimens from these lesions and from the liver showed Kaposi's sarcoma.

Three days later immunosuppression was stopped and by the end of August the reticulonodular shadowing was reduced (fig $3 b$ ). Repeat gastroscopy and computed tomography of abdomen showed virtually normal appearances. The patient was discharged home but had to be readmitted one month later for a transplant nephrectomy. This time his cytomegalovirus antibody titre was raised at 128 . He remains well with regular haemodialysis, with no evidence of recurrence of Kaposi's sarcoma.

\section{Discussion}

The incidence of Kaposi's sarcoma among recipients of renal transplants is reported to be around $4 \%$, which is a $400-500$ fold increase over that seen in a population of similar ethnic origin.' At the Riyadh Military Hospital, among 350 patients who received transplants we have seen 12 cases of Kaposi's sarcoma, giving an incidence of $3.4 \%{ }^{8}$ As in previously reported series, the most common site was the skin, followed by the gastrointestinal tract and lymph nodes.

The two cases reported here presented primarily as a problem of diffuse lung infiltrate in an immunocompromised patient. Skin lesions suggestive of Kaposi's sarcoma developed later and then only minute foci were discovered after careful scrutiny of the skin. Extensive visceral Kaposi's sarcoma, however, particularly of the gastrointestinal tract and the intra-abdominal lymph nodes, was evidently present at the time of presentation and symptoms from these somewhat overshadowed the respiratory symptoms. In fact, the relative paucity of the respiratory symptoms and the relatively well preserved lung function presented a striking contrast to Pneumocystis carinii pneumonia and other opportunistic lung infections.

Several other features were helpful in differentiating lung infiltrates due to Kaposi's sarcoma from those caused by opportunistic infections. The tempo of the disease was slow, the onset and the course developing over several months rather than weeks. Fever was not prominent. In case 1 high fever developed only after the immunosuppression was stopped, and this was probably due to rejection of the transplant kidney rather than to Kaposi's sarcoma. Haemorrhagic pleural effusion with parietal pleural biopsy showing only reactive changes seems to be a characteristic feature of pulmonary Kaposi's sarcoma, as others have also noted. ${ }^{39-11}$

Radiologically the infiltrate consists of irregular nodules of varying size with irregular line shadows extending from these and some background reticulation. This accords well with the histological finding of foci of nodular masses of varying size with infiltrative borders and a lymphatic distribution of these foci in the pleura and septa and along bronchovascular rays. ${ }^{511}$

Transbronchial or bronchial biopsies may not always give the diagnosis because of the focal nature of the lesions, and because penetration through the mucosa is uncommon. ${ }^{5}$ Diagnosis is possible, however, on the basis of bronchoscopic biopsy alone."1-14

Limited Kaposi's sarcoma in recipients of renal transplants-for example, when the lesions are confined to the skin - may regress completely on reduction of the dose of immunosuppressants. ${ }^{78}$ When there is extensive visceral disease, however, the immunosuppressants need to be stopped and the transplant will have to be sacrificed. In both our patients satisfactory resolution of the Kaposi's sarcoma lesions occurred on withdrawal of immunosuppression. In recipients of transplants the outcome of Kaposi's sarcoma is better than in AIDS because the underlying immunosuppression is reversible.

\section{References}

1 Safai B. Kaposi's sarcoma: a review of the classical and epidemic forms. Ann NY Acad Sci 1984;437:373-82.

2 Hutt MSR. Kaposi's sarcoma. Br Med Bull 1984;40:355-8.

3 Meduri GU, Stover DE, Lee M, Myskowsky PL, Caravelli JF, 
Zaman MB. Pulmonary Kaposi's sarcoma in the acquired immune deficiency syndrome: Clinical, radiographic and pathologic manifestations. Am J Med 1985;81:11-8.

4 Ognibine FP, Steis RG, Macher AM, et al. Kaposi's sarcoma causing pulmonary infiltrates and respiratory failure in acquired immunodeficiency syndrome. Ann Intern Med 1985;102:471-5.

5 Purdy LJ, Colby TV, Yousem SA, Battifora H. Pulmonary Kaposi's sarcoma: Premortem histologic diagnosis. Am J Surg Pathol 1986;10:301-11.

6 Pitchenik AE, Fischl MA, Saldana MJ. Kaposi's sarcoma of the tracheobronchial tree: clinical, bronchoscopic and pathologic features. Chest 1985;87:122-4.

7 Harwood AR, Osoba D, Hofstader SL, et al. Kaposi's sarcoma in recipients of renal transplants. Am J Med 1979;67:759-65.

8 Suleiman M, Haleem A, Al-Khader AA. Kaposi's sarcoma after renal transplantation. Transplant Proc 1987;19(1):2243-4.

9 Misra DP, Sunderrajan EV, Hurst DJ, Maltby JD. Kaposi's sarcoma of the lung: radiography and pathology. Thorax
1982;37:155-6.

10 Antman KH, Nadler L, Mark EJ, Montella DL, Kirkpatrick P, Halpern J. Primary Kaposi's sarcoma of the lung in an immunocompetent 32-year-old heterosexual white man. Cancer 1984;54:1696-8.

11 Fouret PJ, Touboul JL, Mayaud CM, Akoun GM, Roland J. Pulmonary Kaposi's sarcoma in patients with acquired immune deficiency syndrome: a clinicopathological study. Thorax 1987; 42:262-8.

12 Ciment LM, Rothbart A, Blaustein A, Galbut RN, Griedler D. Asthma, Kaposi's sarcoma and nodular pulmonary infiltrates. Chest 1983;84:281-2.

13 Kornfield $\mathbf{H}$, Axelrod JL. Pulmonary presentation of Kaposi's sarcoma in a homosexual patient. Am Rev Respir Dis
1983;127:248-9.

14 Hanson PJV, Harcourt-Webster JN, Gazzard BJ, Collins JV. $\frac{\vec{\omega}}{\omega}$ Fibreoptic bronchoscopy in diagnosis of bronchopulmonary $\infty$ Kaposi's sarcoma. Thorax 1987;42:269-71. 